\title{
Influence of non-stoichiometry of sulphides on adsorption isotherms of dyes
}

\author{
D K SENGUPTA, S K ROY* and S C SIRCAR* \\ Mineral Beneficiation Group, Regional Research Laboratory, Bhubaneswar 751013 , India \\ *Department of Metallurgical Engineering, Indian Institute of Technology, Kharagpur \\ 721 302, India
}

\begin{abstract}
Depending on their non-stoichiometry, sulphides are classified as n-type or plype semiconductors. Adsorption of dyes from aqueous and non-aqueous solutions has been made use of to study the surface characteristics of solid adsorbents. Their use in flotation as collectors or depressants is also reported. Adsorption of anionic tartrazine on CdS-doped $\mathrm{Ag}_{2} \mathrm{~S}$ shows a lower value compared to undoped $\mathrm{Ag}_{2} \mathrm{~S}$. The dye adsorption characteristics un these sulphides has been explained on the basis of their defect-structures.
\end{abstract}

Keywords. Non-stoichiometry; dye adsorption; isotherms.

\section{Introduction}

Minerals can be separated by flotation if the surface of the particles can be made selectively hydrophobic by use of surfactants (e.g. collectors) which are selectively adsorbed. Any organic acid, base or salts may be suitable as collectors, if it has specific reactivity, dispersibility and availability (Gaudin 1957). Non-ionic agents are also usea as collectors. A number of dyes have been used as flotation collectors (Spedden 1951) and depressants (Taggart 1954; Schubert 1981). Adsorption of dyes from aqueous and non-aqueous solutions is also used to study the surface characteristics of solid dsorbents.

The present study reports the adsorption behaviour of tartrazine (an anionic dye) and safranine-T (a cationic dye) on n-type sulphides such as $\mathrm{Ag}_{2} \mathrm{~S}, \mathrm{Ag}_{2} \mathrm{~S}$ doped with $\mathrm{CdS}$ and $\mathrm{ZnS}$ and a p-type sulphide such as $\mathrm{PbS}$. Safranine-T has been found to float sulphide minerals effectively (Sengupta et al 1988).

\section{Experimental}

\subsection{Materials}

$\mathrm{Ag}_{2} \mathrm{~S}$ (Mellor 1961) was prepared by passing $\mathrm{H}_{2} \mathrm{~S}$ gas into a solution of $\mathrm{AgNO}_{3}$. In order to dope $\mathrm{Ag}_{2} \mathrm{~S}$ with $\mathrm{CdS}$, a specific quantity of $\mathrm{AgNO}_{3}$ solution was added to get a product containing 0.1 wt. \% CdS. ZnS was prepared (Mellor 1963) from an ammoniacal solution of $\mathrm{ZnCl}_{2}$ which was precipitated as $\mathrm{ZnS}$ by adding a solution of $\mathrm{Na}_{2} \mathrm{~S}$ held in an ice bath. PbS was prepared (Rao et al 1976) from a solution of lead acetate. Lead was precipitated as $\mathrm{PbS}$ in the ice bath by adding $\mathrm{Na}_{2} \mathrm{~S}$ solution.

All the sulphides were thoroughly washed, dried at $343 \mathrm{~K}$, stored in well-stoppered bottles and kept in a dessicator.

Semiconductor types were determined for $\mathrm{ZnS}$ and $\mathrm{PbS}$ using a hot probe method (Balachandran et al 1987). The circuit consisted of a galvanometer connected in series with a copper plate which carried the sulphide specimen in the form of a pellet 
and electrically heated probe. The difference in temperature across the specimen generated a thermoelectric-emf which caused the current to flow. The direction of the current flow indicated the semiconductor type. The above measurement indicated that $\mathrm{ZnS}$ was an $\mathrm{n}$-type semiconductor and $\mathrm{PbS}$ used for the study was p-type semiconductor.

The anionic dye used in the study was tartrazine (GR). Its structure is shown below:<smiles>CS(=O)(=O)c1ccc(N=C=NC2C(C(=O)O[Na])NN(c3ccc([O-])cc3)C2O)cc1</smiles>

$\mathrm{C}_{16} \mathrm{H}_{9} \mathrm{~N}_{4} \mathrm{Na}_{3} \mathrm{O}_{9} \mathrm{~S}_{2}$ (mol. wt 534.37).

This dye has a molecular area of $471 \AA^{2}$ (Orr 1950). The cationic dye used is safranine- $T$ with the following structure<smiles></smiles>

$$
\mathrm{C}_{20} \mathrm{H}_{19} \mathrm{~N}_{4} \mathrm{Cl} \text { (mol. wt 350). }
$$

The molecular area of safranine-T was reported to be $148 \AA^{2}$ (Mishra et al 1984).

Since the molecular areas of these dyes are larger than that of nitrogen, the BET method for the measurement of surface area was not used. The surface area was calculated from the size distribution data obtained on a sedigraph (Micromeritics Corporation, USA, model 5000D) using the method suggested by Allen (1963). However, measurements with a high speed surface area analyser (Micromeritics, USA, model 2200) based on BET principle showed zero area for $\mathrm{Ag}_{2} \mathrm{~S}$ as well as $\mathrm{CdS}$-doped $\mathrm{Ag}_{2} \mathrm{~S}$. Therefore, the surface areas for all the sulphides were calculated from the size distribution data and they were as follows: 1402, 1586, 4182 and $776 \mathrm{~cm}^{2} \mathrm{~g}^{-1}$ for $\mathrm{Ag}_{2} \mathrm{~S}, \mathrm{Ag}_{2} \mathrm{~S}$ doped with $\mathrm{CdS}, \mathrm{ZnS}$ and $\mathrm{PbS}$ respectively.

\subsection{Adsorption measurement}

Adsorption of dyes from aqueous solutions has been determined by the difference between their concentrations before and after adsorption using a photoelectric colorimeter (Klett Summerson, USA). The time required for attaining equilibrium adsorption of the dyes and the time provided in the experiments are presented in table 1.

The amount of dye chemisorbed on $\mathrm{Ag}_{2} \mathrm{~S}$, CdS-doped $\mathrm{Ag}_{2} \mathrm{~S}$ and $-\mathrm{PbS}$ has been estimated by a difference method. After equilibrium adsorption of the dyes, the 
lable 1. Time required for equilibrium adsorption of dyes.

\begin{tabular}{|c|c|c|c|c|}
\hline \multirow[b]{2}{*}{ Sample } & \multicolumn{2}{|c|}{ Tartrazine adsorption } & \multicolumn{2}{|c|}{ Safranine-T adsorption } \\
\hline & $\begin{array}{l}\text { Minimum time } \\
\text { requirement } \\
\text { (h) }\end{array}$ & $\begin{array}{c}\text { Time } \\
\text { provided } \\
\text { (h) }\end{array}$ & $\begin{array}{l}\text { Minimum time } \\
\text { requirement } \\
\text { (h) }\end{array}$ & $\begin{array}{l}\text { Time } \\
\text { provided } \\
\text { (h) }\end{array}$ \\
\hline $\begin{array}{l}\text { Silver sulphide } \\
\text { system }\end{array}$ & 40 & 72 & 6 & 16 \\
\hline Zinc sulphide & 48 & 96 & 24 & 48 \\
\hline Lead sulphide & 60 & 120 & 40 & 72 \\
\hline
\end{tabular}

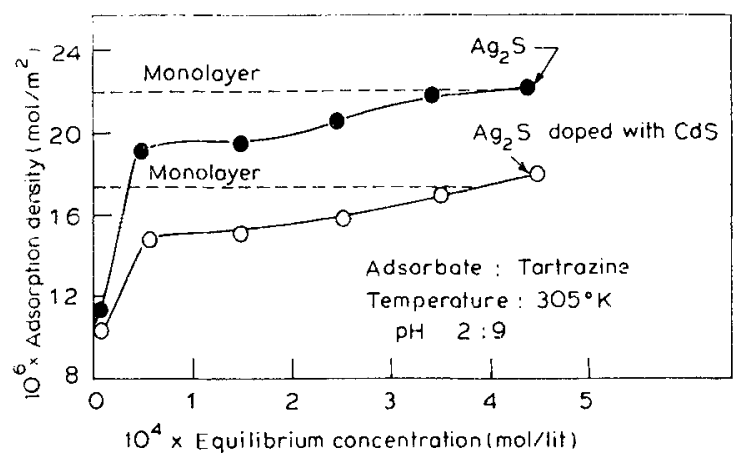

Fïgure 1. Adsorption isotherms of tartrazine on $\mathrm{Ag}_{2} \mathrm{~S}$ and its doped variety.

adsorbents were washed with distilled water till the washed water showed no coloration. The total dye content in the washed water was deducted from the initial amount to determine the amount of dye chemisorbed on the surfaces or not desorbed from the surface. In the case of $\mathrm{ZnS}$, it was dissolved in $1: 1 \mathrm{HCl}$ after thorough washing. Chemisorption was estimated according to the method of Norman (1970).

\section{Results}

Adsorption isotherms of tartrazine on $\mathrm{Ag}_{2} \mathrm{~S}$ and $\mathrm{CdS}$-doped $\mathrm{Ag}_{2} \mathrm{~S}$ are shown in figure 1. The $\mathrm{pH}$ of tartrazine in contact with the powder samples of $\mathrm{Ag}_{2} \mathrm{~S}$ and $\mathrm{Ag}_{2} \mathrm{~S}$ doped with $\mathrm{CdS}$ did not show any significant change within the range of dye concentration studied. The $\mathrm{pH}$ was around 2.9 for tartrazine and varied between 2.8 and 3.0 for safranine-T. The adsorption isotherms of safranine- $\mathrm{T}$ on $\mathrm{Ag}_{2} \mathrm{~S}$ and $\mathrm{CdS}$ doped $\mathrm{Ag}_{2} \mathrm{~S}$ are shown in figure 2. In the case of tartrazine adsorption, isotherms for both the samples were of H-type according to the classification given by Giles et al (1960). The Langmuir plots (figure 3) were based on the equation

$$
C / M=\left(C / M^{\prime}\right)+(b / a)\left(1 / M^{\prime}\right),
$$

where $C$ is the equilibrium concentration in mol/l, $M$ the amount adsorbed in $\mathrm{mol} / \mathrm{g}$ of the sample, $M^{\prime}$ the amount adsorbed to form a monolayer in mole/g of the sample and $a, b$ the constants referring to monolayer adsorption. Figure 3 shows the plots between $C / M$ in $\mathrm{g} / \mathrm{l}$ vs $C$ in $\mathrm{mol} / \mathrm{l}$. The monolayer capacities obtained from the 


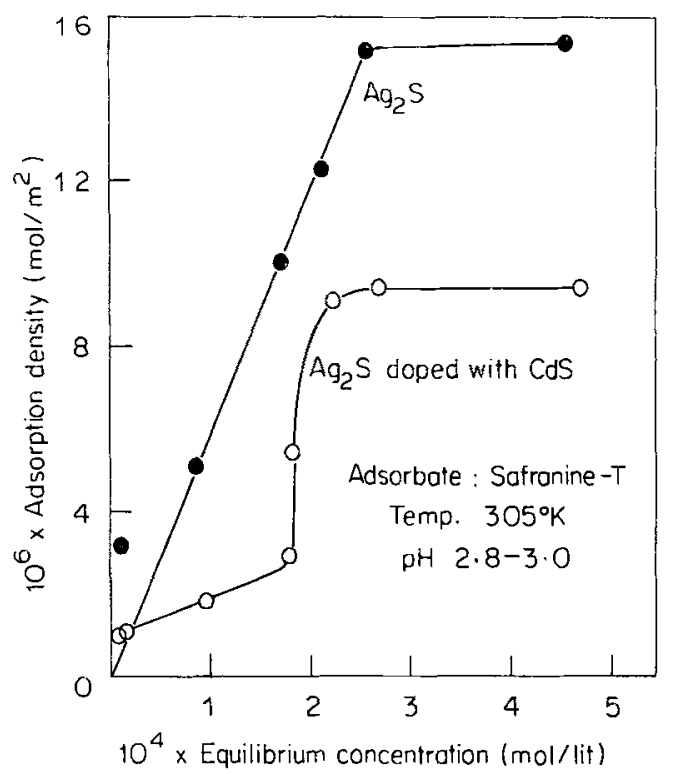

Figure 2. Adsorption isotherms of safranine-T on $\mathrm{Ag}_{2} \mathrm{~S}$ and its doped variety.

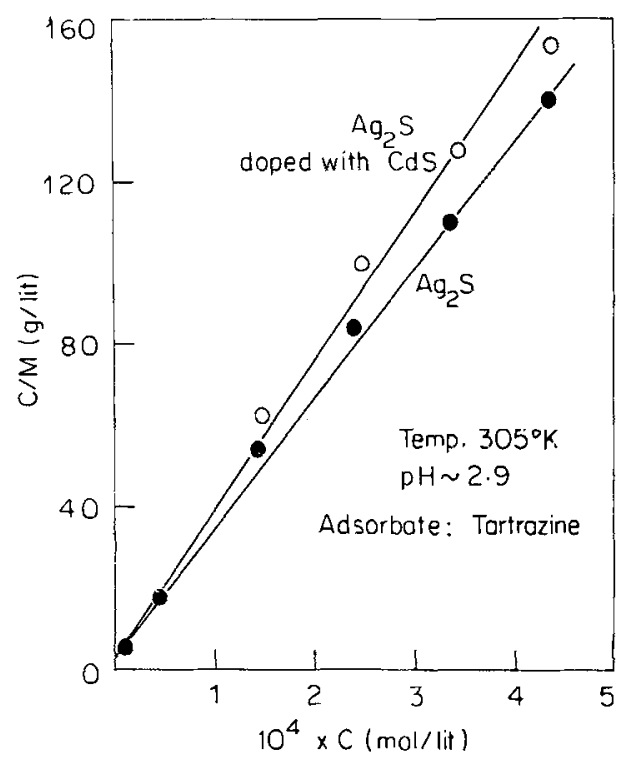

Figure 3. Langmuir plots for adsorption of tartrazine on $\mathrm{Ag}_{2} \mathrm{~S}$ and its doped variety.

(slope) ${ }^{-1}$ of the straight lines in figure 3 were found to be $3.0941 \times 10^{-6}$ and $2.7503 \times 10^{-6} \mathrm{~mol} / \mathrm{g}$ respectively or $22.069 \times 10^{-6}$ and $17.344 \times 10^{-6} \mathrm{~mol} \mathrm{~m}^{-2}$ respectively.

The adsorption isotherms of safranine- $\mathrm{T}$ on undoped $\mathrm{Ag}_{2} \mathrm{~S}$ (figure 2) closely resemble with C-type adsorption curve (Giles et al 1960). Beyond the equilibrium concentration of $2.75 \times 10^{-4} \mathrm{~mol} / \mathrm{l}$, the adsorption reached a saturation and the 
quantity adsorbed was $2.13 \times 10^{-6} \mathrm{~mol} \mathrm{~g}^{-1}$ or $15.27 \times 10^{-6} \mathrm{~mol} \mathrm{~m}{ }^{2}$. The CdS-doped $\mathrm{Ag}_{2} \mathrm{~S}$ showed a two-stage adsorption of safranine-T. The first stage may be compared to C-type curve and around $1.9 \times 10^{-4} \mathrm{~mol} / 1$ of equilibrium concentration, it suddenly rises and shows a plateau region beyond $2.2 \times 10^{-4} \mathrm{~mol} / \mathrm{l}$ of equilibrium concentration. The amount of safranine- $T$ adsorbed at this stage was $1.48 \times$ $10^{-6} \mathrm{~mol} / \mathrm{g}$ or $9.31 \times 10^{-6} \mathrm{~mol} \mathrm{~m}{ }^{-2}$. It is seen that the isotherm of safranine-T does not follow (Sengupta 1985) any of the relations like Freundlich, Langmuir or BET.

The adsorption isotherms of tartrazine and safranine- $\mathrm{T}$ on $\mathrm{ZnS}$ depicted in figure 4 resemble with S-type curve (Giles et $a l 1960$ ) and both of them follow a more or less Freundlich relation according to the following relation

$$
\log (x / m)=\frac{1}{n} \log C+\log k
$$

where $x$ is the amount adsorbed in $g$ by ' $m$ ' $g$ of adsorbent, $C$ the equilibrium concentration in $\mathrm{g} / \mathrm{l}$ and $n, k$ the constants. Figure 5 shows plots between $\log C$ vs $\log (x / m)$ which gives slopes of about 1.43 and 1.36 respectively.

The adsorption isotherms of tartrazine and safranine-T on $\mathrm{PbS}$ are shown in figure 6. The tartrazine adsorption on $\mathrm{PbS}$ shows resemblance to L-type curve (Giles et al 1960) and follows a Langmuir relation (figure 5). The monolayer capacity as calculated from (slope) $)^{-1}$ is $3.0 \times 10^{-5} \mathrm{~mol} / \mathrm{g}$ or $38.7 \times 10^{-5} \mathrm{~mol} \mathrm{~m}^{-2}$. The adsorption isotherm of safranine- $\mathrm{T}$ on $\mathrm{PbS}$ resembles an S-type curve and follows more or less the Freundlich equation with a high slope value of 2.85 (figure 5). For $\mathrm{Ag}_{2} \mathrm{~S}$ system the $\mathrm{pH}$ was around 2.9 . In the $\mathrm{ZnS} /$ tartrazine system, the $\mathrm{pH}$ was within 7.6 to 8.2 in which range the adsorption showed a constant value (Sengupta 1985) starting from $7 \cdot 2$. In the case of $\mathrm{ZnS} /$ safranine- $\mathrm{T}$ system, the $\mathrm{pH}$ was within $7 \cdot 3$ to 7.5 and the variation seen in adsorbed dye was insignificant. In the case of $\mathrm{PbS}$, the $\mathrm{pH}$ was within $5 \cdot 7$ to $6 \cdot 0$. A summary of the results is given in table 3 .

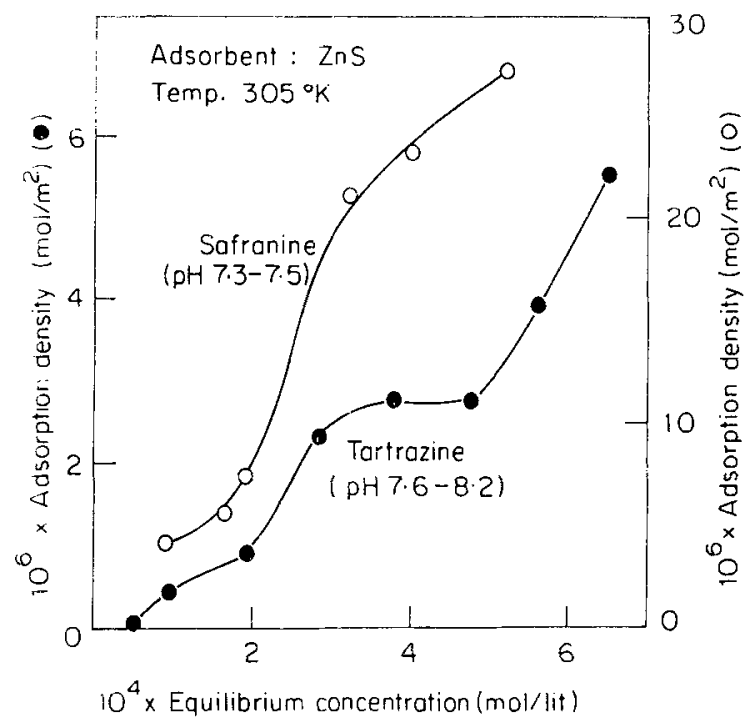

Nigure 4. Adsorption isotherms of tartrazine and salranine-T on $\mathrm{ZnS}$. 


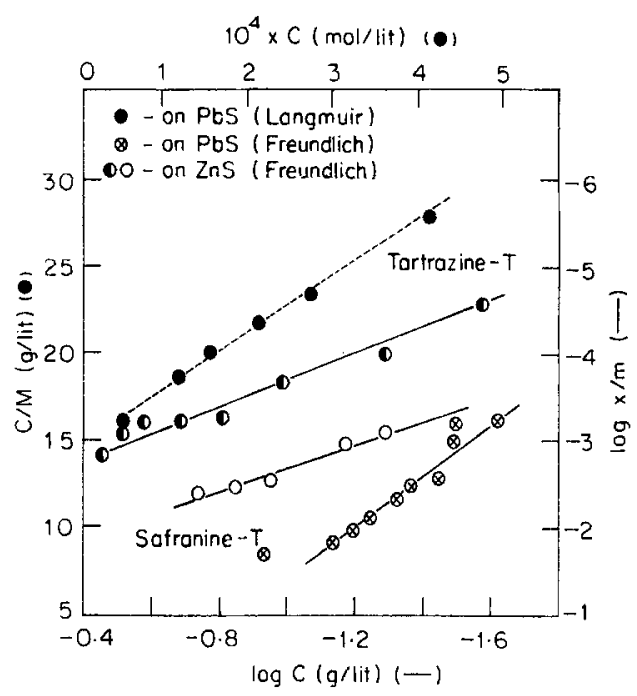

Figure 5. Freundlich and Langmuir plots for adsorption of dyes on $\mathrm{ZnS}$ and $\mathrm{PbS}$.

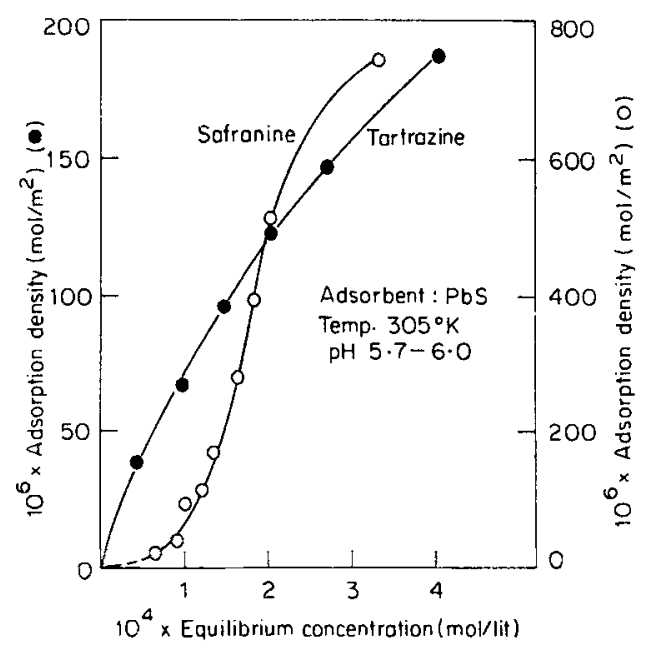

Figure 6. Adsorption isotherms of tartrazine and safranine-T on $\mathrm{PbS}$.

\section{Discussion}

Adsorption isotherms of tartrazine on $\mathrm{Ag}_{2} \mathrm{~S}$ and $\mathrm{Ag}_{2} \mathrm{~S}$ doped with $\mathrm{CdS}$ appear to resemble with $\mathrm{H}$-type curve (Giles et al 1960) characterizing a high, affinity of tartrazine towards both $\mathrm{Ag}_{2} \mathrm{~S}$ and its doped variety. The chemisorption data (table 2) show that around $60 \%$ of the total adsorption is perhaps contributed by the chemisorption process. This implies that there may be some chemical binding force between $\mathrm{Ag}_{2} \mathrm{~S}$ and the anionic tartrazine. $\mathrm{Ag}_{2} \mathrm{~S}$ is an $\mathrm{n}$-type semiconductor (Wagner 1953) with slight excess of silver ions and free electron. However, the excess silver ion is expected to occupy interstitial positions as suggested by Hauffe (1965). When $\mathrm{Ag}_{2} \mathrm{~S}$ 
Table 2. Results on chemisorption of dyes un diflerent sulphides.

\begin{tabular}{|c|c|c|c|c|}
\hline Adsurbent & Adsorbate & $\begin{array}{c}\text { Initial } \\
\text { concentration } \\
(\mathrm{mol} / \mathrm{l})\end{array}$ & $\begin{array}{c}\text { Total } \\
\text { adsorption } \times 10^{-6} \\
\left(\mathrm{~mol} / \mathrm{m}^{2}\right)\end{array}$ & $\begin{array}{c}\text { Amount not } \\
\text { desorbed by } \\
\text { washing } \\
\left(\mathrm{mol} / \mathrm{m}^{2}\right)\end{array}$ \\
\hline Pure $\mathrm{Ag}_{2} \mathrm{~S}$ & $\mathrm{~T}$ & $3 \times 10^{-4}$ & $20 \cdot 6$ & $\begin{array}{c}12.41 \times 10^{-6} \\
(60.2 \%)\end{array}$ \\
\hline CdS-doped $\mathrm{Ag}_{2} \mathrm{~S}$ & $\mathbf{T}$ & $3 \times 10^{-4}$ & $15 \cdot 72$ & $\begin{array}{c}8.93 \times 10^{-6} \\
(56.8 \%)\end{array}$ \\
\hline Pure $\mathrm{Ag}_{2} \mathrm{~S}$ & $S$ & $2.9934 \times 10^{-4}$ & $15 \cdot 27$ & Negligible \\
\hline CdS-doped $\mathrm{Ag}_{2} \mathrm{~S}$ & $S$ & $2.9934 \times 10^{-4}$ & $9 \cdot 31$ & do- \\
\hline $\mathrm{PbS}$ & $\mathrm{T}$ & $1.0769 \times 10^{-6}$ & $38-46$ & $\begin{array}{c}15.68 \times 10^{-6} \\
(40.8 \%)\end{array}$ \\
\hline PbS & $S$ & $1 \times 10^{-4}$ & $20 \cdot 67$ & $\begin{array}{c}8.28 \times 10^{-7} \\
(4.0 \%)\end{array}$ \\
\hline $\mathrm{LnS}$ & $T$ & $6 \times 10^{-4}$ & 3.91 & Negligible \\
\hline $\mathrm{ZnS}$ & $S$ & $2.1184 \times 10^{-4}$ & 5.67 & $\begin{array}{c}1.43 \times 10^{-6} \\
(25.3 \%)\end{array}$ \\
\hline
\end{tabular}

T. tartrazine; $\mathrm{S}$, safranine- $\mathrm{T}$.

is doped with CdS, the defect equilibria may be written as

or

$$
\mathrm{CdS}=\mathrm{Cd}_{\mathrm{Ag}}^{\circ}+e^{\prime}+S_{S}
$$

$$
\mathrm{CdS}=\mathrm{Cd}_{\mathrm{Ag}}^{\circ}+V_{\mathrm{Ag}}^{\prime}+S_{S},
$$

where $\mathrm{Cd}_{\mathrm{Ag}}^{\prime}, e^{\prime}$ and $V_{\mathrm{Ag}}^{\prime}$ represent $\mathrm{Cd}^{2+}$ ion occupying $\mathrm{Ag}^{+}$ion position with a positive charge, a negatively charged electron and a negatively charged silver vacancy respectively. Excess electron and negatively charged cation vacancy created by doping is expected to decrease the adsorption of anionic tartrazine. The monolayer capacity as calculated from the Langmuir plots is, therefore, smaller for $\mathrm{CdS}$-doped $\mathrm{Ag}_{2} \mathrm{~S}$ compared to undoped $\mathrm{Ag}_{2} \mathrm{~S}$. Therefore the experimental results agree with the surface condition predicted due to the effects brought about by doping with higher valent metal ion.

The C-type curve obtained for the adsorption of safranine- $\mathrm{T}$ on $\mathrm{Ag}_{2} \mathrm{~S}$ is characterized by the constant partition of safranine- $T$ between $\mathrm{Ag}_{2} \mathrm{~S}$ and dye solution up to the maximum possible adsorption. Such a curve indicates that as more safranine- $T$ is adsorbed, more sites for adsorption are created. The process suddenly stops when highly crystalline regions of the substrate are reached and the isotherm shows a plateau region. This is attributed to the varying degree of crystallinity in $\mathrm{Ag}_{2} \mathrm{~S}$ system. However, such a curve appears mainly with textile fibres (Kipling 1965).

If the adsorption isotherms of tartrazine and safranine- $\mathrm{T}$ on $\mathrm{Ag}_{2} \mathrm{~S}$ and $\mathrm{CdS}$-doped $\mathrm{Ag}_{2} \mathrm{~S}$ are compared, it is seen that both tartrazine (anionic) and safranine- $\mathrm{T}$ (cationic) are adsorbed less on $\mathrm{CdS}$-doped $\mathrm{Ag}_{2} \mathrm{~S}$ than on undoped $\mathrm{Ag}_{2} \mathrm{~S}$. The basic difference regarding adsorption of dyes as found from the experimental results is that the adsorption of tartrazine on $\mathrm{Ag}_{2} \mathrm{~S}$ system is perhaps governed mostly by chemisorption whereas the adsorption of safranine- $T$ is purely a physisorption process. When the n-type $\mathrm{Ag}_{2} \mathrm{~S}$ is increased by $\mathrm{Cd}^{2+}$ doping, the surface prefers to adsorb more $\mathrm{H}^{+}$ions compared to the cationic dye leading to a decrease in the adsorption of cationic dye, whereas the negatively charged cation vacancies or excess 


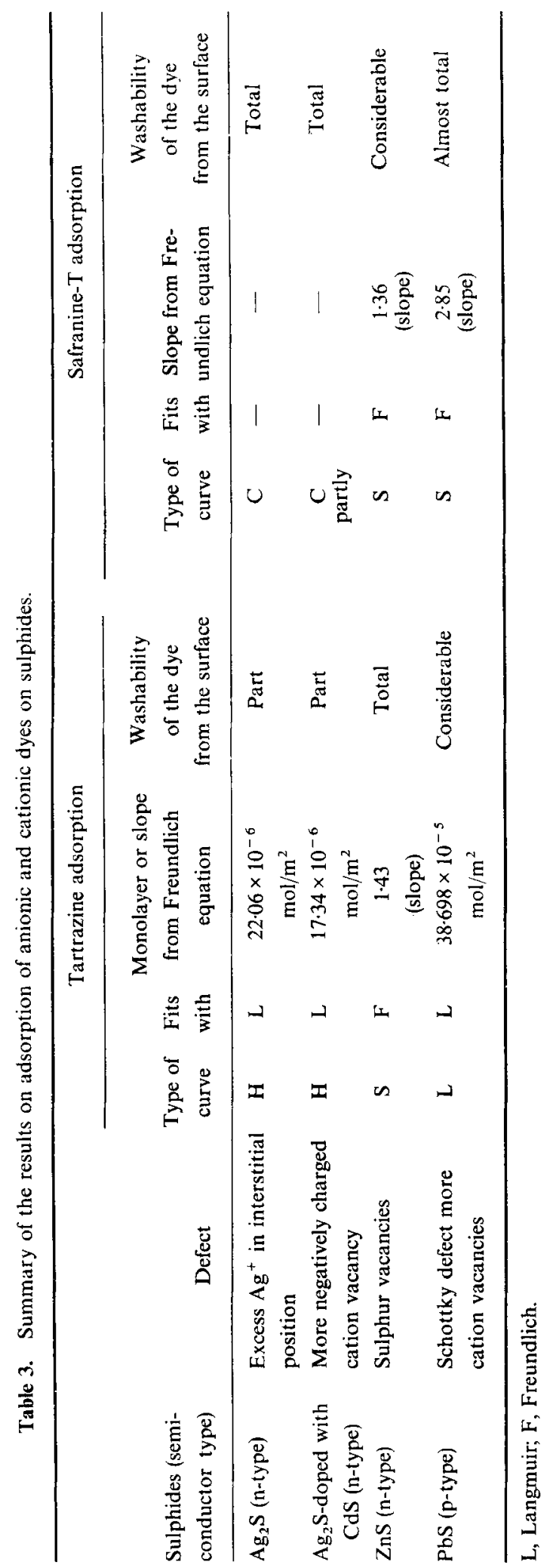


electrons arising out of CdS doping decrease the adsorption of anionic tartrazine.

In the case of $\mathrm{ZnS}$ which is an n-type semiconductor (Kröger 1974) with sulphur vacancy, the adsorption isotherms of tartrazine and safranine-T resemble the S-type curve. For anionic tartrazine adsorption, the initial part of the S-curve perhaps indicates a strong competition between the dye molecule and water molecule for surface sites on $\mathrm{ZnS}$. Since $\mathrm{ZnS}$ is an $\mathrm{n}$-type semiconductor with excess electron, the anionic dye adsorption becomes difficult. With increase in concentration of the dye, the adsorption curve goes up which indicates that one molecule helps the other to get adsorbed on the surface. A further rise beyond the plateau region may be due to adsorption through micelles and therefore, the slope value of the Freundlich plot is quite high.

Adsorption of safranine- $T$ also resembles the S-type curve and the slope value from Freundlich plot is quite high i.e. about 1.36. The contribution due to chemisorption was estimated to be around $25 \%$ of the total adsorption and the rest is by physisorption. It has been reported by Fuerstenau (1957) that when Freundlich plots yield slope values more than 0.5 , the adsorption process is either through chemical interaction with the surface metal ion or through micelle formation. Safranine-T perhaps first interacts chemically with the surface metal ions and as the concentration of the dye is increased, the adsorption process continues with the micelle formation.

Bloem (1963) reported that PbS exhibits a predominantly Schottky defect. In the present case, cation vacancies are greater compared to anion vacancies imparting a p-type behaviour, viz

$$
\frac{1}{2} S_{2}=\mathrm{PbS}+V_{\mathrm{Pb}}^{\prime \prime}+2 h \text {. }
$$

Hence, the doubly-charged negative lead vacancy $\left(V_{\mathrm{Pb}}^{\prime \prime}\right)$ and positive hole $(\dot{h})$ are present.

The adsorption isotherm of anionic tartrazine on $\mathrm{PbS}$ resembles an L-type curve (Giles et al 1960) and this isotherm fits well with the Langmuir relation. Experiments for estimation of chemisorption indicate that a considerable part of the total adsorption, i.e. around $40 \%$ is contributed by chemisorption which may be due to the positive holes.

Adsorption isotherm of safranine- $\mathrm{T}$ on $\mathrm{PbS}$ shows a very good resemblance to $\mathrm{S}$ type curve (Giles et al 1960) and it follows more or less a Freundlich relation as shown in figure 5 with a high slope value. Estimation of chemisorption shows that the adsorption is mostly governed by the physical process. The high slope value in the Freundlich plot, therefore, indicates that the greater adsorption of safranine- $T$ is probably due to the adsorption of micelles.

\section{Acknowledgements}

The authors acknowledge helpful discussions with Dr S B Kanungo. They are also thankful to the Director for providing facilities.

\section{References}

Allen T 1963 Particle size measurement (London: Chapman and Hall) p. 222

Balachandran S B, Simkovich G and Aplan F F 1987 Int. J. Miner. Process. 21157 
Bloem J 1963 Philips Res. Rep. 11273

Fuerstenau D W 1957 Chemistry of bio-surfaces (ed.) M L Hair (New York: Marcel Deck Inc.) p. 182

Gaudin A M 1957 Flotation (New York: McGraw Hill) 2nd edn. p. 182

Giles C H, MacEwan T H, Nakhaw S N and Smith D 1960 J. Chem. Soc. 3973

Hauffe K 1965 Oxidation of metals (New York: Plenum Press) p. 365

Kipling J J 1965 Adsorption from solutions of non-eiectrolytes (London: Academic Press) p. 90

Kröger F A 1974 The chemistry of imperfect crystals (Amsterdam: North Holland) 2nd edn.

Mellor J W 1961 A comprehensive treatise on inorganic and theoretical chemistry (London: Longmans) Vol. 3 p. 438

Mellor J W 1963 A comprehensive treatise on inorganic and theoretical chemistry (London: Longmans) Vol. 4 p. 586

Mishra R K, Mundhara G L, Tiwari J S and Moitra S 1984 J. Indian Chem. Soc. 6144

Norman V J 1970 Aust. J. Chem. 232171

Orr C J 1950 Project 145-68 Georgia Institute of Technology, State Engineering, Experiment Station, Atlanta, Special Report No. 1

Rao S R, Moon K S and Leja J 1976 Flotation-A M Gaudin Memorial Volume (ed.) M C Fuerstenau (New York: Inst. Min. Met. Petrol Eng. Inc.) Vol. 1 p. 509

Rush H Spedden 1951 Encyclopedia of chemical technology (eds) R E Kirk and D F Othmer (New York: Interscience Encyclopedia Inc.)

Sengupta D K 1985 Ph.D. thesis, Indian Institute of Technology, Kharagpur

Sengupta D K, Roy S K and Sircar S C 1988 Int. J. Miner. Process. 23151

Schubert H 1981 Proc. Int. Symp. on Recent Advances in Beneficiation and Agglomeration of Minerals (ed.) K S Narasimhan (Bhubaneswar: RRL) 6.42.1

Taggart A F 1954 Handbook of mineral processing (New York: John Wiley) p. 12-25

Wagher C 1953 J. Chem. Phys. 211819 